\title{
GREEN SYNTHESIS OF SILVER NANOPARTICLES USING PLANTS ORIGINATING IN TROPICAL AREAS OF VIETNAM FOR BIOLOGICAL APPLICATIONS
}

\author{
1,2,3Karel SEHNAL, ${ }^{4}$ Phi Thi LY, 1,2Dagmar UHLIROVA, ${ }^{4}$ Mai Le DUNG, 1,2Martina STANKOVA, \\ ${ }^{4}$ Tran Thanh XUAN, ${ }^{1,4}$ Michaela VSETICKOVA, ${ }^{4} \mathrm{Ngo}$ Ngoc ANH, ${ }^{1,2,5}$ Bozena HOSNEDLOVA, \\ ${ }^{6}$ Marta KEPINSKA, ${ }^{1,3}$ Branislav RUTTKAY-NEDECKY, ${ }^{4}$ Duong Ngoc BACH, \\ ${ }^{6}$ Halina MILNEROWICZ, ${ }^{7}$ Tejo PRAKASH, ${ }^{4}$ Nguyen The HUNG, ${ }^{4}$ Hoai Viet NGUYEN, \\ 1,2,3,5,6Rene KIZEK
}

${ }^{1}$ Department of Viticulture and Enology, Faculty of Horticulture, Mendel University in Brno, Lednice, Czech Republic, EU, karelsehnal15@gmail.com

${ }^{2}$ Department of Research and Development, Prevention Medicals s.r.o., Studenka-Butovice, Czech Republic, EU, uhlirova@preventionmedicals.cz

${ }^{3}$ Department of Human Pharmacology and Toxicology, University of Veterinary and Pharmaceutical Sciences Brno, Czech Republic, EU, kizek@sci.muni.cz

${ }^{4}$ Research Center for Environmental Monitoring and Modelling, VNU University of Science, Thanh Xuan district, Hanoi, Vietnam, nguyenviethoai@hus.edu.vn

${ }^{5}$ Department of Food and Feed Safety, Veterinary Research Institute, Brno, Czech Republic, EU, bozena.hosnedlova@post.cz

${ }^{6}$ Department of Biomedical and Environmental Analyses, Faculty of Pharmacy with Division of Laboratory

Diagnostics, Wroclaw Medical University, Wroclaw, Poland, EU, zalewska.m@gmail.com

${ }^{7}$ School of Energy and Environment, Thapar Institute of Engineering and Technology, Patiala, India, tejoprakash@gmail.com

https://doi.org/10.37904/nanocon.2019.8522

\begin{abstract}
Silver nanoparticles (AgNPs) exhibit excellent antibacterial effects against both Gram-positive and Gramnegative bacteria. They represent a possible way to combat bacteria resistant to conventional antibiotic treatment. Over time, bacteria also become resistant to AgNPs. One solution is to modify the AgNP surface with various simple or more complex biomolecules with antibacterial activity. Such modifications can be achieved using so-called green synthesis. The green synthesis of AgNPs is based, for example, on the use of plant extracts as reducing agents. The AgNPs obtained have biomolecules derived from the extract bound to their surface. The aim of this work was to identify other plant species with a high content of secondary metabolites with the potential antibacterial activity that would make them suitable for green synthesis. A large number of plants occurring in tropical areas of Vietnam contain a lot of hitherto unspecified substances with the potential antibacterial effect. Nanoparticles prepared using extracts of harvested plants were characterized by physical and biochemical methods. Silver nanoparticles with the modified surface can be used to combat resistant bacteria.
\end{abstract}

Keywords: Ethnobotany, biochemical analysis, antioxidant activity

\section{INTRODUCTION}

In recent years, nanotechnology is developing rapidly and is being used in all sectors of human activity. Nanomaterials, due to the excellent antibacterial effect, are being explored for possible health applications [1]. Nanoparticles can also be used for their physicochemical properties suitable as tags in sensor / biosensor analysis [2,3]. Green synthesis introduces new technologies that are more compatible with biological systems and molecules. Various kinds of plant-derived biomolecules can be used for such synthesis [4]. In addition, 
the synthesized nanoparticles can be coated with a cationic polyelectrolyte layer to further enhance the nanoparticle effect [5]. Adhesive hydrogels are of great popularity in biomedical applications, but there are a number of adhesion and antibacterial problems. Lignin hydrogels with silver nanoparticles (AgNPs) have been designed to significantly improve these properties. Lignin hydrogels with AgNPs have been designed to significantly improve these properties [6]. For example, different ways how to prepare various AgNPs-based nanotransporters for targeted therapy of tumour or bacterial diseases are being sought. The antibacterial properties of AgNPs are most studied and discussed [5,7]. However, their biological effect is still not very clear and must be carefully studied $[8,9]$. Indeed, AgNPs are characterized not only by antibacterial but also antiviral, antifungal [10] and antitumor effects [11]. The aim of this work was to prepare AgNPs with the modified surface to increase their antibacterial abilities and to test this activity. By using green synthesis, such modifications can be easily achieved. Typical for green synthesis is the use of plant extracts that replace chemical reducing agents in the reaction, such as $\mathrm{NaBH}_{4}$ or $\mathrm{LiAlH}_{4}$. Tropical and subtropical forests represent a great potential as there is a large number of endemic plant species in which a lot of chemical compounds (low-molecularweight substances) as well as biologically important molecules (peptides, proteins, nucleic acids, etc.), have been described. Especially phenolic substances, namely flavonoids, are important in antibacterial activity.

\section{MATERIAL AND METHODS}

Biological material collection sites have been selected in the cooperation with CEMM researchers. Plant samples were collected in the university campus of the VNU University of Science, Thong Nhat and Tuoi Tre part, Hoan Kiem lake, and Hanoi Botanical Garden, Hanoi Night Market, Tu Dung Homestay Botanic Garden in Can Tho and Cat Tien National Park. All activities were handled in direct collaboration with workplaces at Vietnamese universities. Plant species were collected in tropical forest areas in Vietnam as a part of a scientific expedition in July 2019. Six plant species were selected. GPS coordinates were recorded for each plant. Plants used in experiments were as follows: Lagerstroemia indica, Lagerstroemia speciosa, Alstonia scholaris, Polyalthia longifolia, Aglaonema multifolium, and Delonix regia. Individual plant species were classified into families and genera primarily by the appearance of their leaves, stems, and overall plant appearance. Alternatively, flowers or fruits were used to identify plants. Plant identification was provided by the Department of Pharmacognosy of the Faculty of Pharmacology at Tra Vinh University.

Short description of nanoparticle preparation: Immediately after collection, the plants were washed in distilled water and divided into smaller parts. Subsequently, all samples were transferred to a Petri dish and placed in an oven (HN101, Lang-Shan, China) for 24 hours at $60^{\circ} \mathrm{C}$. The samples were then homogenized to a fine homogeneous powder using a mixer (Mixer Grinder HL1643/06, Philips, Netherlands). The material thus prepared was used to prepare the plant extract. $1 \mathrm{~g}$ of the prepared plant material was mixed with $50 \mathrm{~mL}$ of distilled water heated to $80^{\circ} \mathrm{C}$. Extraction was carried out for 1 hour with stirring (IKA RH basic, Malaysia) at $80^{\circ} \mathrm{C}$ and $300 \mathrm{~g}$. Each plant extract was filtered and allowed to cool to room temperature. After filtration, the plant extracts were mixed with $0.1 \mathrm{M} \mathrm{AgNO}_{3}(1: 1)$ and allowed to stir with a magnetic stirrer (IKA RH basic, Malaysia) at room temperature $\left(23^{\circ} \mathrm{C}\right)$ for 18 hours. During the formation of nanoparticles, the colour of the resulting solution gradually changed (increasing the absorbance in the area of $450 \mathrm{~nm}$ due to the formation of nanoparticles).

VIS absorption spectra were measured in the $250-750 \mathrm{~nm}$ range. (Biochemical analysis of AgNPs surface was performed on BS-300 automatic analyzer (Mindray, China). DPPH (2,2-diphenyl-1-picrylhydrazyl), ABTS (2,2'-azino-bis(3-ethylbenzothiazoline-6-sulfonic acid) and FRAP (ferric reducing ability of plasma) methods were used for sample analysis $[12,13]$. Infinite F50, (Tecan, Switzerland) was used to measure bacterial growth curves. The antimicrobial activity of the AgNPs prepared by green synthesis was determined by the microdilution method, with some modifications. Different volumes of the stock solution AgNPs and broth media were added to 96 -well microtiter plates to obtain tested concentrations with a final volume of $250 \mu \mathrm{L}$. Then a $1-10 \mu \mathrm{L}$ of the microbial inoculums were inoculated in microtiter plate wells to obtain a final concentration of 
$10^{4}$ cells $/ \mathrm{mL}$. The plates were incubated for $24 \mathrm{~h}$ at $30^{\circ} \mathrm{C}$ and after incubation, viable cell numbers were enumerated, and the colony-forming units per millilitre $(\mathrm{CFU} / \mathrm{mL})$ were determined. Positive and negative controls were included in all assays. Probit analysis used to determine the minimum inhibitory concentrations (Qinslab Information System, Czech Republic).

\section{RESULTS AND DISCUSSION}

In the experimental work, AgNPs were prepared by green synthesis with yields between 60 - $80 \%$ depending on the individual plant species used for the synthesis.
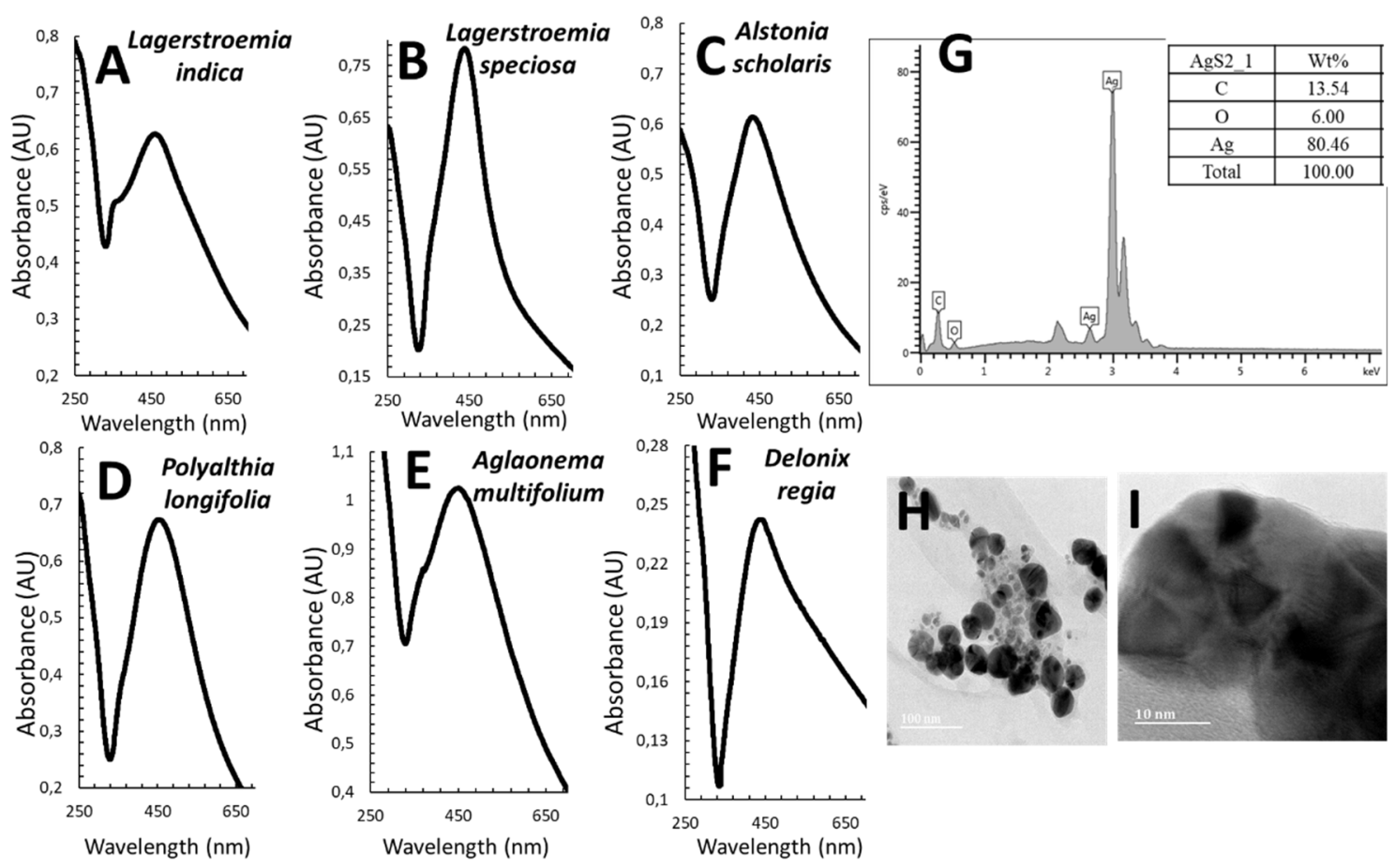

Figure 1 Typical absorption spectra of AgNPs: (A) Lagerstroemia indica, (B) Lagerstroemia speciosa, (C) Alstonia scholaris, (D) Polyalthia longifolia, (E) Aglaonema multifolium, (F) Delonix regia. (G) XRD analysis of AgNPs $(H, I)$ HRTEM analysis of AgNPs. Other experimental details are given in Material and Methods part.

Evidence of formation of AgNPs was indicated by the presence of absorption maxima of about $450 \mathrm{~nm}$ (Figure 1). Spherical AgNPs showed only one peak. The more the absorption maximum was shifted to higher wavelengths, the larger the AgNPs were. The appearance of peaks with a smaller area under the curve at lower wavelengths confirmed the presence of monodisperse nanoparticles. On the other hand, peaks with a larger area under the curve at higher wavelengths confirmed the presence of polydispersion. Characterization of AgNPs: The size of nanoparticles ranged from $20-60 \mathrm{~nm}$, which is similar to the average size $(27 \mathrm{~nm})$ of those prepared by Nicolescu et al. [14] that found the maximum peak at $400-440 \mathrm{~nm}$. On the contrary, some researchers reported the maximum peak in the area of $340-620 \mathrm{~nm}$ [15]. The HRTEM analysis confirmed a polyhedron shaped AgNPs. By obtaining the XRD spectrum, we confirmed the presence of carbon and oxygen on the surface of AgNPs (Figure 1).

In further experiments nanoparticles were characterized in terms of secondary metabolites bound to their surface. AgNPs were dispersed in ultrapure water, with $40 \mathrm{~W}$., ultrasound for $30 \mathrm{~min}$ and then analysed. Chemical analysis (phenolic compounds, ABTS, DPPH, FRAP) showed the presence of phenolic groups on the AgNPs surface. The total concentrations of phenolic compounds and the ability of AgNPs to quench free oxygen radicals are summarized in Figure 2. The highest concentration of phenolic compounds was found in 
AgNPs prepared with $L$. speciosa extract. The most significant antioxidant activity, measured by ABTS method was observed in $A$. scholaris, by DPPH method in P. longifolia and by FRAP method in $A$. scholaris.
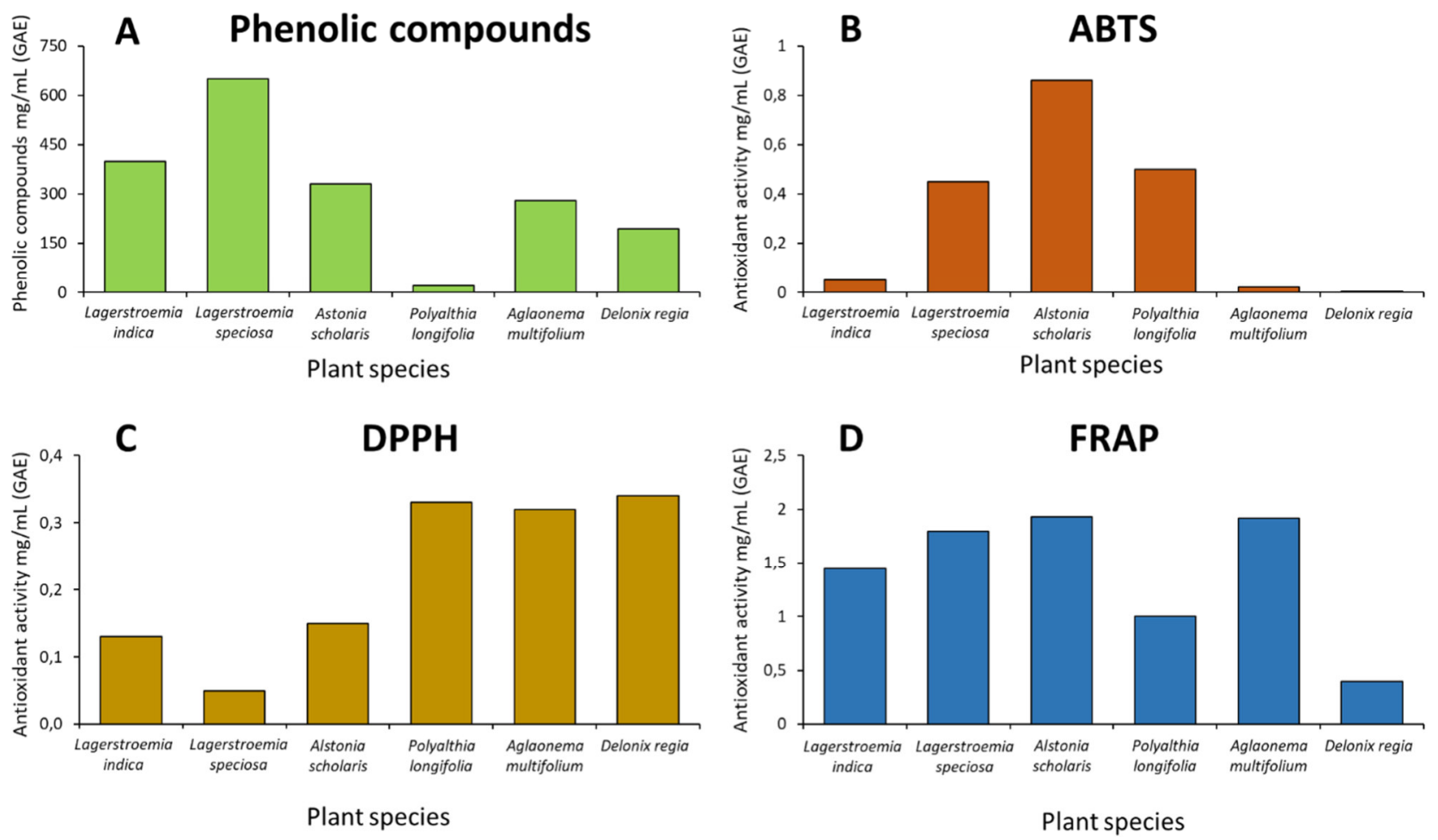

Figure 2. Biochemical characterization of AgNPs. (A) Concentrations of total phenolic compounds on the surface of AgNPs. (B, C, D) AgNPs ability to quench free oxygen radicals - ABTS, DPPH, and FRAP methods. GAE- gallic acid equivalent.

Antibacterial activity was monitored for Gram-positive S. aureus and M. luteus, for Gram-negative E. coli and S. marcescens. In the diffusion test, the diffusion zones about $1.5-2 \mathrm{~cm}$ were observed. Growth curves and Probit analysis showed minimal inhibitory concentrations between $0.8-5 \mathrm{mg} / \mathrm{ml}$. The highest antibacterial effect was shown for AgNPs form A. multifolium. This nanoparticle form have moderately high concentration of phenolic compounds and have strongly high ability to generate free oxygen radicals, especially FRAP. The lowest MIC value was shown for AgNPs from P. longifolia. We can suggest, that the concentration of phenolic compounds correlates with antibacterial properties of green synthesis silver nanoparticles. The highest susceptibility to silver nanoparticles in our experiment was shown for $E$. coli strain. There is no significantly difference, between AgNPs effect on Gram-positive and Gram-negative bacteria $(p<0.05)$ see in Table 1.

Table 1 - Effect of green synthesized AgNPs on bacterial cells in diffusion test

\begin{tabular}{|c|c|c|c|c|}
\hline Treatment & $\begin{array}{c}\text { AgNPs from } \\
\text { L. indica }\end{array}$ & $\begin{array}{c}\text { AgNPs from } \\
\text { A. scholaris }\end{array}$ & $\begin{array}{c}\text { AgNPs from } \\
\text { P. longifolia }\end{array}$ & $\begin{array}{c}\text { AgNPs from } \\
\text { A. multifolium }\end{array}$ \\
\hline E. coli & $<0.8$ & 1.3 & 1.6 & $<0.8$ \\
\hline S. marcescens & $<0.8$ & 1.3 & 5 & 0.8 \\
\hline S. aureus & 2.5 & 1.3 & 3.2 & $<0.8$ \\
\hline M. luteus & 1.3 & 1.3 & 5 & $1.3-0.8$ \\
\hline
\end{tabular}

Minimal inhibition concentration (MIC) of AgNPs is given in $\mathrm{mg} / \mathrm{mL}$ 


\section{CONCLUSIONS}

We have prepared silver nanoparticles using a green synthesis approach in which plant extracts prepared from plant species collected in Vietnam were used. In these areas, there are many plant species in which not all secondary metabolites have been described in detail. However, these substances may have potential antibacterial activity. Using the green synthesis, the AgNPs surface can be modified with these substances to improve their antibacterial activity. Such nanoparticles can be used to combat bacterial resistance very effectively. Our results show that applying the principles of green chemistry can allow the synthesis of nanoparticles with biologically important molecules that have higher antimicrobial activity and less impact on environment than nanoparticles prepared by chemical synthesis.

\section{ACKNOWLEDGEMENTS}

The work was carried out with the support of the H2020 CA COST Action CA15114, INTER-COST LTC18002. We thank Prof. Augustine Ofomaja for performing an electron microscopic analysis of AgNPs.

\section{REFERENCES}

[1] HUSSAIN, M., RAJA, N. I., IQBAL, M., ASLAM, S. Applications of Plant Flavonoids in the Green Synthesis of Colloidal Silver Nanoparticles and Impacts on Human Health. Iranian Journal of Science and Technology Transaction a-Science, 2019, vol. 43, no. A3, pp. 1381-1392.

[2] KOKER, T., TANG, N., TIAN, C., ZHANG, W., WANG, X. D., MARTEL, R., PINAUD, F. Cellular imaging by targeted assembly of hot-spot SERS and photoacoustic nanoprobes using split-fluorescent protein scaffolds. Nature Communications, 2018, vol. 9, no. pp. 17.

[3] MA, W., MA, H., PENG, Y. Y., TIAN, H., LONG, Y. T. An ultrasensitive photoelectrochemical platform for quantifying photoinduced electron-transfer properties of a single entity. Nature Protocols, 2019, vol. 14, no. 9, pp. 2672-2690.

[4] KUMAR, A., VEMULA, P. K., AJAYAN, P. M., JOHN, G. Silver-nanoparticle-embedded antimicrobial paints based on vegetable oil. Nature Materials, 2008, vol. 7, no. 3, pp. 236-241.

[5] RICHTER, A. P., BROWN, J. S., BHARTI, B., WANG, A., GANGWAL, S., HOUCK, K., HUBAL, E. A. C., PAUNOV, V. N., STOYANOV, S. D., VELEV, O. D. An environmentally benign antimicrobial nanoparticle based on a silver-infused lignin core. Nature Nanotechnology, 2015, vol. 10, no. 9, pp. 817-+.

[6] GAN, D. L., XING, W. S., JIANG, L. L., FANG, J., ZHAO, C. C., REN, F. Z., FANG, L. M., WANG, K. F., LU, X. Plant-inspired adhesive and tough hydrogel based on Ag-Lignin nanoparticles-triggered dynamic redox catechol chemistry. Nature Communications, 2019, vol. 10, no. pp. 10.

[7] GURUNATHAN, S. Rapid biological synthesis of silver nanoparticles and their enhanced antibacterial effects against Escherichia fergusonii and Streptococcus mutans. Arabian Journal of Chemistry, 2019, vol. 12, no. 2, pp. 168-180.

[8] NEDERBERG, F., ZHANG, Y., TAN, J. P. K., XU, K. J., WANG, H. Y., YANG, C., GAO, S. J., GUO, X. D., FUKUSHIMA, K., LI, L. J., HEDRICK, J. L., YANG, Y. Y. Biodegradable nanostructures with selective lysis of microbial membranes. Nature Chemistry, 2011, vol. 3, no. 5, pp. 409-414.

[9] HU, C. M. J., FANG, R. H., WANG, K. C., LUK, B. T., THAMPHIWATANA, S., DEHAINI, D., NGUYEN, P., ANGSANTIKUL, P., WEN, C. H., KROLL, A. V., CARPENTER, C., RAMESH, M., QU, V., PATEL, S. H., ZHU, J., SHI, W., HOFMAN, F. M., CHEN, T. C., GAO, W. W., ZHANG, K., CHIEN, S., ZHANG, L. F. Nanoparticle biointerfacing by platelet membrane cloaking. Nature, 2015, vol. 526, no. 7571, pp. 118-+.

[10] KARAMIAN, R., KAMALNEJAD, J. Green Synthesis of Silver Nanoparticles Using Cuminum cyminum Leaf Extract and Evaluation of Their Biological Activities. Journal of Nanostructures, 2019, vol. 9, no. 1, pp. 74-85. 
[11] RUdDARAJU, L. K., PAllela, P., PAMMI, S. V. N., PADAVALA, V. S., KOLAPALLI, V. R. M. Synergetic antibacterial and anticarcinogenic effects of Annona squamosa leaf extract mediated silver nano particles. Materials Science in Semiconductor Processing, 2019, vol. 100, no. pp. 301-309.

[12] OU, B. X., HUANG, D. J., HAMPSCH-WOODILL, M., FLANAGAN, J. A., DEEMER, E. K. Analysis of antioxidant activities of common vegetables employing oxygen radical absorbance capacity (ORAC) and ferric reducing antioxidant power (FRAP) assays: A comparative study. Journal of Agricultural and Food Chemistry, 2002, vol. 50, no. 11, pp. 3122-3128.

[13] RE, R., PELlEgRINI, N., PROTEggente, A., PANNALA, A., YANG, M., RICE-EVANS, C. Antioxidant activity applying an improved ABTS radical cation decolorization assay. Free Radical Biology and Medicine, 1999, vol. 26, no. 9-10, pp. 1231-1237.

[14] BUMBAC, M., OLTEANU, R. L., ION, R. M., NICOLESCU, C. M. Influence of Temperature on the Growth of Silver Nanoparticles Synthesized Using Salvia officinalis Aqueous Extract. Revista De Chimie, 2018, vol. 69, no. 8, pp. 1934-1938.

[15] BAGHAYERI, M., MAHDAVI, B., ABADI, Z. H. M., FARHADI, S. Green synthesis of silver nanoparticles using water extract of Salvia leriifolia: Antibacterial studies and applications as catalysts in the electrochemical detection of nitrite. Applied Organometallic Chemistry, 2018, vol. 32, no. 2, pp. 9. 